\title{
ESTADO CAPITALISTA, POLÍTICAS PÚBLICAS E REPRODUTIVISMO EDUCACIONAL
}

\author{
Claudionor Ferreira Araújo ${ }^{1}$ \\ Carlos Roberto da Silva Machado ${ }^{2}$
}

\section{Resumo:}

A avaliação de políticas públicas, como as de educação, precisa identificar que tipo de Estado as implementa e a que fins esse Estado se propõe. Buscamos, aqui, uma definição entre políticas de Estado ou de Governo e até onde este consegue alcançar e agir e em favor de que ou de quem ele age. Este trabalho se propõe apresentar tais definições como base para reflexão sobre a implementação das políticas públicas, especialmente educacionais, no atual modelo de Estado. E conclui-se pelo papel da educação em reproduzir o modelo social vigente em favor de quem domina o Estado.

Palavras-chave: Estado, Capitalismo e Educação.

\begin{abstract}
:
The evaluation of public policies, as well as education policies, needs to identify what kind of State implements them and what this State intends to do. We intend to find a definition between State or Government policies and see how far it can reach and act and in favor of what or whom he acts. This paper offers to present such definitions as basis to reflection concerning the implementation of public policies, especially educational ones, in the current model of State. And it concludes by the role of education in reproducing the current social model, in favor of those who dominate the state.
\end{abstract}

Keywords: State, Capitalism and Education.

\section{Considerações iniciais}

Uma análise, mesmo que superficial, sobre políticas públicas, especialmente na área educacional, deve considerar, entre outros fatores, aqueles que são distintivos e distinguidores das ações de Estado para e com a sociedade "realmente existente", que é desigual, ou seja, a riqueza produzida, o território e o "uso" dos "espaços" de poder não

\footnotetext{
${ }^{1}$ Doutorando em Educação Ambiental (PPGEA/FURG), Mestre em Educação (Políticas Públicas) pela Universidade Federal do Pará - UFPA.

${ }^{2}$ Doutor em Educação pela UFRGS. Professor titular de Políticas Públicas da Educação na Fundação Universidade Federal do Rio Grande (FURG) e na Linha de Fundamentos da Educação Ambiental no Programa de Pós-Graduação em Educação Ambiental.
} 


\section{ESTADO CAPITALISTA, POLÍTICAS PÚBLICAS E...}

\section{Claudionor Ferreira Araújo / Carlos Roberto da Silva Machado}

é utilizado (apropriado) de forma igualitária ou as políticas não se desenvolvem em beneficio equânime a todos os cidadãos. Trata-se de um "pano de fundo" não estático ou dado para todo sempre, mas permanentemente "produzido e re-produzido" (conforme Henri Lefebvre, cf. MACHADO; MARTINS, 2011). E tendo-o como referência, devemos, pois, considerar, seja a avaliação, seja os posicionamentos em relação à definição das ações, tidas por políticas públicas, inclusive aquelas voltadas à educação, o que são ações de Estado e ações de Governo.

Nesse caso, é debate corrente que as ações de Estado seriam aquelas mais abrangentes, que na temporalidade ou na universalidade, ou seja, seriam mais duradouras e diriam respeito a todos. Afirmaremos que tal debate é a outra moeda do mesmo debate liberal, que coloca o Estado como "neutro" ou "acima" das classes, ou, da desigual apropriação da riqueza e dos territórios pelos diferentes grupos sociais.

Para tal abordagem, desenvolvemos, antes, uma base teórica de crítica efetiva sobre o modelo social em vigor, juntamente com seu modo de produção capitalista e os aparelhos ideológicos do Estado, por meio dos quais o modelo social se impõe econômica, política e ideologicamente através dos agentes (burocracia) gestores dos "espaços de poder". A partir desse ponto, fazemos uma aproximação entre a análise conjuntural, a crítica social e a educação, esta como política pública de um Estado comprometido com a manutenção do atual quadro social.

E assim posto, o Estado não pode lidar com o conflito, a diversidade de projetos, a desigualdade. Mas, se o faz, é para justificar que o seu projeto pretende unir e superar tais questões, pois "fala" em nome de todos, como se fora "um único" no conteúdo dos discursos. Por fim, apresentamos as possibilidades de estudo das políticas públicas de educação numa perspectiva "radical” como de "partilha do sensível” (RANCIERE, 2005) em contraposição àqueles discursos, sejam dos grupos que estão no Estado (governo), seja dos grupos dominantes àqueles aliados ou com eles divergentes.

\section{Das tendências marxistas ao reprodutivismo em Bourdieu e Passeron}

Como base teórica, partimos das contribuições de Bourdieu e Passeron (1975), ou seja, de que a escola e a educação são parte de um processo de reprodução superestrutural. Segundo esses dois autores, mesmo a relativa autonomia da superestrutura, defendida por Althusser (1985) e, aqui no Brasil, por Saviani (2008), ou seja, sua capacidade de reação às imposições sociais se constitui não mais que outro

\begin{tabular}{|l|l|l|l|l|}
\hline Revista Dialectus & Ano 1 & n. 2 & Janeiro-Junho 2013 & p. 180-194 \\
\hline
\end{tabular}


elemento ideologizante. Dessa ideológica "autonomia”, é que se prolifera, hoje, no senso comum, a tese da educação como "salvadora" da sociedade ou como solução para todas as mazelas sociais. Nada além de um "requentar" da teoria do capital humano de Teodore Schultz (cf. MACHADO, 2011). Ora, a reprodução social circunscreve-se às determinações do "campo" e, nesse caso, do "campo" econômico e político, controlador das ações do Estado e de sua estrutura.

Assim, além dessas duas tendências evolutivas do pensamento moderno - da reprodução social pelos elementos superestruturais do Estado, com ou sem autonomia relativa, capacidade de reação, de Althusser e de Bourdieu e Passeron, respectivamente -, usamos também outros autores, cujas ideias possam ser combinadas para efeito de afirmação da tendência aqui adotada.

Entre essas tendências dentro da tradição marxista, há propostas centradas nas ações do Estado, cujo objetivo restringe-se à garantia da produção e da reprodução de meios necessários à consecução da finalidade básica do modo de produção: a acumulação do capital. E há outras tendências, cuja análise sobre as ações do Estado consegue vislumbrar certa autonomia do aparato estatal diante do conflito entre o setor detentor de capital e o proletariado em geral, com possibilidade de oferecer, por ação própria, melhores condições de trabalho, ou mesmo, valorização desse trabalho. Trata- se, pois de tendências de caráter mais reformista (cf. SOREL, 1992).

A proposta de Althusser, de uma crítica reprodutivista, consiste da aproximação do estruturalismo ao marxismo, da qual formula a análise estruturalista da teoria marxista - ou marxismo estruturalista. Nessa análise, entende, entre outras proposições, que o materialismo histórico "é a teoria da natureza específica desta 'totalidade orgânica' ou estrutura e, portanto, do conjunto de seus 'níveis' e do tipo de articulação e de determinação que os une uns aos outros.” (ALTHUSSER; BADIOU, 1979, p. 35). Logo, se constitui a teoria da história, que tem como objeto o modo de produção, cuja formação deriva da combinação de diversas estruturas.

Segundo Althusser (1985), existem conflitos na base decorrentes da luta de classes, como identifica também Carnoy (1990). Assim, a política da estrutura se reproduzirá na superestrutura, mas esta é determinada "em última instância" pela base. Os novos direcionamentos determinados por uma mudança de classe na condição de dominante, na base, portanto, se reproduzem na estrutura pela nova política econômica do Estado e desemboca em mudanças também na superestrutura, como o caso da escola. 


\section{Claudionor Ferreira Araújo / Carlos Roberto da Silva Machado}

A escola se constitui um caso especial na produção de Althusser (Ibidem). Para ele, a escola figura como o dominante entre os Aparelhos Ideológicos do Estado (AIE). Enquanto na sociedade feudal, o AIE principal era político e tinha na Igreja seu principal instrumento, é sobre o AIE escolar que repousa, na sociedade burguesa, a maior atenção. Logo, dado o tempo que as crianças estão expostas a ela e a postura reacionária (reprodutora) da maioria dos professores em favor do sistema e da ideologia vigentes, a escola se tornou um poderoso instrumento de ideologização na mão daqueles que agem por meio dela, sob a face "neutra" do Estado. E é nesse sentido que Henri Lefebvre (a partir de Hegel, cf. LEFEBVRE, 1975) afirma que a classe média (como burocracia), ao assumir ou gerir as instituições, busca, em conformidade aos interesses dominantes, se colocar acima da materialidade ou dos interesses gerais da sociedade. O Estado é

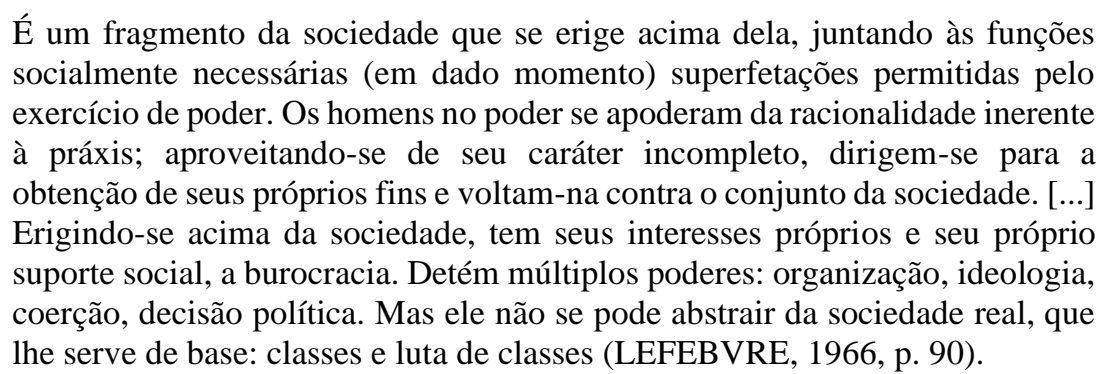

Logo, sua presumida "neutralidade" ou "imaterialidade" se constitui outro elemento ideológico e ideologizante, por meio da qual transfere os valores da classe dominante como se fossem universais - a violência simbólica de Bourdieu e Passeron (1975).

Esses dois autores concordam com Althusser quanto à função da escola de reproduzir e legitimar as relações entre as classes para a manutenção da ordem instituída. Mas discordam da possibilidade de uma autonomia relativa da superestrutura em relação à estrutura, proposta por Althusser (1985), que daria àquela a capacidade para uma reação às imposições desta e mesmo a existência de reciprocidade entre as ações dessas duas instâncias.

Tais características estão previstas na tradição marxista brasileira, como bem se vê defendidas por Saviani (2008) em sua pedagogia histórico-crítica. Para Saviani, embora a escola sofra a ação da sociedade que a determina, também reage a ela, o que pode ocasionalmente provocar mudanças nesta última. Ou, nas palavras de Carnoy, "as ações na escola têm o potencial de contribuir positivamente para a posição do trabalho

\begin{tabular}{|l|l|l|l|l|} 
Revista Dialectus & Ano 1 & n. 2 & Janeiro-Junho 2013 & p. 180-194 \\
\hline
\end{tabular}


na luta de classes, através da relação orgânica entre a luta na superestrutura e a luta na base" (CARNOY, 1990, p. 86).

Para Bourdieu e Passeron (1975), mesmo essa autonomia relativa da escola não passa de uma fachada para a reprodução da hierarquia social. Um exemplo claro dessa análise é o dito caráter "meritocrático" da escola, que, segundo os autores, é mera idealização, pois na realidade o sucesso escolar e conseguintemente o profissional estão reservados para os alunos oriundos da classe dominante, o que deixa evidente que a realidade do processo de ensino e seleção é de natureza classista. Destacaríamos ainda o habitus, como construção pregressa e relacionada tanto à origem social quanto aos processos de formação de cada um; ou a correlação de forças ou os diferentes posicionamentos no campo educacional, os quais, em sua relação ao campo econômico e político, subordinariam as possibilidades transformadoras da educação.

Além disso, como afirmamos sobre a apropriação desigual, bem como da relação entre as classes e os grupos sociais com a materialidade (e diríamos sobre a própria compreensão dessas relações), o ponto de partida em que se desenvolve a educação é desigual aos atores sociais. Nesse sentido, urge a necessidade de articular a educação e as políticas educacionais (seja o discurso sobre a educação bem como sobre as políticas) com esse ponto de partida desigual.

\section{Políticas: de Estado ou de Governo? Públicas ou privadas?}

A definição de política pública precisa partir da distinção entre Estado e Governo, para, daí, depurar se ela abrangeria as ações de ambos, ou se seria aproximada mais de uma que de outra distinção. Nesse caso, dizemos ser as ações de Estado relacionadas àquelas "mais de fundo", mais de longo prazo ou que dissessem respeito a todos; e as de governo, àquelas outras mais imediatas, de curto prazo e restritas, talvez, aos 04 (quatro) anos de uma gestão governamental no Brasil. E como tal, a partir de Lefebvre (1966), diríamos que, o Estado seria uma "abstração" que se materializa nos "governos" (seus instrumentos de fazer-se, de materializar-se, inclusive as políticas e a educação) em função dos interesses dominantes explicitados na correlação desigual de forças, tendo a apropriação da materialidade, já referida, como "pano de fundo". O Estado, como construção humana, tende a se autonomizar ao colocar-se acima da materialidade (à semelhança da religião) e pretendendo falar (a burocracia gestora do Estado) em nome de toda a sociedade.

\begin{tabular}{|l|l|l|l|l|}
\hline Revista Dialectus & Ano 1 & n. 2 & Janeiro-Junho 2013 & p. 180-194 \\
\hline
\end{tabular}




\title{
ESTADO CAPITALISTA, POLÍTICAS PÚBLICAS E...
}

\section{Claudionor Ferreira Araújo / Carlos Roberto da Silva Machado}

Nesse sentido, mas numa compreensão diferente da nossa, mesmo que também numa perspectiva crítica, Eloísa Höfling (2001, p. 32) aponta que

\begin{abstract}
é possível se considerar Estado como o conjunto de instituições permanentes - como órgãos legislativos, tribunais, exército e outras que não formam um bloco monolítico necessariamente - que possibilitam a ação do governo; e Governo, como o conjunto de programas e projetos que parte da sociedade (políticos, técnicos, organismos da sociedade civil e outros) propõe para a sociedade como um todo, configurando-se a orientação política de um determinado governo que assume e desempenha as funções de Estado por um determinado período.
\end{abstract}

Por um lado, concordamos com Höfling (2001), que as políticas públicas seriam as ações do Estado quando da implementação de programas ou projetos de um governo, voltadas para setores específicos da sociedade, e nesse caso, relacionado a sua definição de governo. No entanto, diferimos de seu argumento de que tal definição não ficaria reduzida à burocracia pública, responsável pela concepção e implementação das políticas públicas. Mas sim como o responsável pela "implementação e manutenção a partir de um processo de tomada de decisões, que envolve órgãos públicos e diferentes organismos e agentes da sociedade relacionada à política implementada.” (HÖFLING, 2001, p. 32).

De outro lado, Machado $(2005,2006)$ ao argumentar sobre a diferenciação das definições de política, oferece três possibilidades de interpretação: polity, policy e politics. Ou seja, as teorias ou as referências teóricas (polity), as políticas concretas e/ou específicas (policy) e as relações políticas ou processo de implementação das políticas (politics). Argumenta o autor que o estudo, a pesquisa e a análise das políticas deveriam considerar esses três aspectos, conforme o lugar em que o analista se encontra (seja para manutenção ou defesa da política em desenvolvimento; ou ao contrário, desde uma perspectiva radical de superação do que está instituído), além do envolvimento dos atores nas definições do que é uma ou outras. Consequentemente, políticas públicas seriam entendidas como uma ação (politics) além das que correspondem a políticas estatais (policy); bem como aquilo que está como não referido, relacionado aos referenciais, aos paradigmas, etc. que dizem respeito à utopia de sociedade, de educação, etc., que tem a ver com a teoria política (polity) de base da análise daquele que escreve ou argumenta.

Nesses termos, a educação - objeto mais específico deste estudo - poderia ser assumida como uma política pública (policy) e, no que se refere à participação de vários interesses envolvidos no processo de tomada de decisões, abrangeria as ações 
necessárias a sua efetivação (politics), mas também, aos fins do Estado e das políticas (polity). Conforme Teixeira, já relacionado a um conteúdo, as políticas públicas consistiriam na base das ações do poder público, nas relações desse com a sociedade, isto é, uma espécie de "mediação entre atores da sociedade e do estado" (TEIXEIRA, 2002, p. 2); ou, ao contrário, pelas “não ações”, ou omissões como manifestação de políticas, uma vez que decorrem das opções tomadas por aqueles que exercem o poder público. Em ambos os casos, pode-se relacionar às definições que realizamos acima.

Na opinião de Höfling e Teixeira, uma política, para configurar-se pública, deveria considerar a participação de vários atores da sociedade, que representassem, portanto, a vontade de uma coletividade mais ampla, não apenas os interesses de um único segmento social. Nesse caso, a política pública, em nossa perspectiva, estaria relacionada à idéia de politics, em relação aos processos de implementação das políticas e, portanto, à participação dos atores nas políticas.

Nesses termos, conclui Santos et al (2005) que, se as instituições públicas não adotam políticas públicas, de fato, conforme definição de Höfling e Teixeira, é porque essas instituições respondem a outra lógica que não a do poder público a serviço de toda a sociedade (todas as camadas sociais). Dessa forma, trata-se da lógica em que instituições ditas públicas representam "as relações de produção material de uma sociedade dividida em classes, onde uma classe social detém o poder econômico, e, por extensão, o poder político, sobre as demais." (SANTOS et al, 2005, p. 12).

Trata-se de um contraprincípio: se para que uma política se constitua pública é necessário o atendimento aos interesses de toda a coletividade social, logo quando apenas um grupo - a classe social dominante - é a única beneficiária, ou ao menos a principal, a política, mesmo de Estado, se configura de interesse privado. Ou seja, os "espaços de poder" são utilizados em benefícios de determinados grupos sociais, no caso, os dominantes. Do mesmo modo, concluem os autores:

\footnotetext{
Desta forma, podemos dizer que na conjuntura atual não falamos de políticas públicas, pois as mesmas não são definidas pela coletividade, nem sempre estão voltados para o bem comum e, normalmente, são realizadas para garantir a expansão capitalista ou amenizar os efeitos negativos da irracionalidade da acumulação privada - o que agrava a sua busca pela legitimidade no encaminhamento de ações que amenizem o grau de insatisfação social. (SANTOS et al., 2005, p. 13-14).
}

Segundo os autores, o Estado Capitalista, em que estão inseridas quase todas as nações do mundo, inclusive o Brasil, expressa, não a vontade da maioria da população, mas sim os interesses da classe que se apropria da riqueza, do território ou dos "meios

\begin{tabular}{|l|l|l|l|l|}
\hline Revista Dialectus & Ano 1 & n. 2 & Janeiro-Junho 2013 & p. 180-194 \\
\hline
\end{tabular}




\section{ESTADO CAPITALISTA, POLÍTICAS PÚBLICAS E...}

\section{Claudionor Ferreira Araújo / Carlos Roberto da Silva Machado}

necessários" à produção das coisas necessárias à vida, impondo aos demais suas perspectivas e buscando a reprodução das relações sociais. Sendo assim, "não pode, na prática, ser considerado um ente público, defensor dos interesses coletivos" (SANTOS et al., 2005, p. 13). Trata-se, portanto, de um Estado de classe, logo privado, não público, e utilizado em beneficio de uns em detrimento da maioria. Apesar de os discursos se apresentarem em nome de todos, ou buscarem isso, e ainda desenvolverem ações de participação, fazem-no apenas para referendar suas decisões, muitas vezes já tomadas.

\section{Estado Capitalista, Políticas Públicas e Educação}

Numa dada sociedade capitalista, é plausível admitir que os discursos hegemônicos proponham que a educação seja uma política de Estado, na medida em que, por essa ação, seja entendido apenas o aspecto burocrático de seu cumprimento, como propunha Höfling (2001). Este, por exemplo, é um dos aspectos dominantes dos discursos e argumentos dos gestores do capital, hoje, no governo federal e no Ministério da Educação. Mas, segundo eles, se contrapõem às políticas imediatistas (uma gestão) ou ao discurso e proposta das classes empresariais, apenas focadas na formação de mão de obra, as novas necessidades do capital (flexibilização, inovação, determinados hábitos e atitudes, competências etc.). A educação é, nessa perspectiva, uma política oriunda da sociedade (política pública), e corresponde, portanto, a uma ação da sociedade para a promoção de um bem à própria sociedade que deve ser inserida no debate concreto entre as classes e os grupos em disputa em cada momento concreto.

A depender do modelo de sociedade em que se constitui tal Estado, a educação se constituirá, assim, a promoção do bem-estar público ou privado, uma vez que o Estado tem como papel a manutenção das relações sociais em qualquer modelo de sociedade em que seja constituído. Sendo assim, deve-se considerar o modelo em vigor, que no nosso caso é capitalista, portanto. E, como tal, da sua parte,

tem seus valores voltados para a manutenção da supremacia econômica e política de uma determinada classe ou fração de classe social sobre as demais, estando a maioria da população na posição de dominada, pois a acumulação privada tem uma limitação concreta (possível a um pequeno número de pessoas), visto que se baseia na exploração de uma parte da mão- de-obra disponível, enquanto a outra parte é destituída, provisoriamente (talvez permanentemente), do direito ao trabalho, formando aquilo que Marx denominou de "exercito de reserva", uma das causas da pobreza contemporânea. (Grifo do autor). (SANTOS et al, 2005, p. 13). 


\section{Claudionor Ferreira Araújo / Carlos Roberto da Silva Machado}

Nesse modelo, de classes sociais, as ações do Estado, inclusive a educação, promovem, conforme esse entendimento, a manutenção do sistema de classes. Em outras palavras, a perpetuação do abismo social entre ricos e pobres também se efetiva, através da reprodução, pelas políticas de Estado, dos elementos inerentes à estrutura social mais ampla (ALTHUSSER, 1985).

Conforme Santos et al (2005, p.13), a explicação para essa lógica repousa sobre a própria base do sistema capitalista.

O sistema capitalista realiza-se sobre a premissa da exploração, pois se baseia
na acumulação privada de riqueza, onde um grupo tem mais recursos materiais
do que aquilo que é necessário para sua sobrevivência, estabelecendo, assim,
um excedente para uns, que só se sustenta pela escassez de outros (grupos
sociais das classes oprimidas e mantidas em suas instáveis posições).

Em suma, é no contexto de um Estado Capitalista que a educação se insere, e como política de Estado é utilizada, conforme preconizam Bourdieu e Passeron (1975), pela ação do Estado para a reprodução da realidade social. E a escola, instituição pela qual o Estado formaliza a educação (MÉSZÁROS, 1985), recebe o papel de Aparelho Ideológico do Estado (ALTHUSSER, 1985), com a tarefa de formar (reproduzir) para a sociedade os futuros cidadãos, sob as mesmas relações que dela recebe de favorecimento de alguns e exclusão de muitos.

E mais que isso, se se considerar pelo prisma do "arbitrário cultural" (BOURDIEU; PASSERON, 1975), a educação, como qualquer política de Estado, recebe o mesmo status de "neutralidade" que têm as leis e normas do Estado. Ora, não há neutralidade no Estado, ou como diz Pereira (2011), não é possível sequer pensar em um Estado neutro. Logo, se o Estado não é neutro, as leis implementadas por meio dele, (e no dito estado democrático, capitalista, é sempre por meio dele).

Um exemplo dessa ausência de neutralidade nas leis, é-nos oferecido por Araújo (2011) no caso da Lei 9.795/99, que institui a Política Nacional de Educação Ambiental. Segundo esse autor, as leis são um espaço de conflitos (nos termos bakhtinianos da análise do discurso) e sua elaboração não se constitui uma superação de tais conflitos. Ao contrário, aponta sim para a reprodução dos conflitos nos mesmos termos da força política a que eles representam. Ou seja, a lei sempre favorece ao grupo hegemônico dos conflitos políticos de base. Assim, a referida lei, embora seja oferecida em resposta às demandas de populações que a reclamaram por décadas, recebeu um texto que responde muito mais aos interesses daqueles que sempre se opuseram a sua implementação. 


\section{Claudionor Ferreira Araújo / Carlos Roberto da Silva Machado}

E a educação, como política pública efetivada a partir da implementação de uma lei do/pelo Estado, torna-se, assim, um braço do sistema capitalista. E tem como objetivo garantir, para o futuro, que as relações sociais, tais como a exclusão de muitos dos bens do Estado em favor de uns poucos e a concentração de riqueza nas mãos desses poucos, continue sendo considerado "normal" e "natural". E que qualquer contestação dessas relações tenha um caráter imoral, uma vez que tanto as leis quanto as políticas do Estado são difundidas e internalizadas pelas instituições "públicas" e privadas.

\section{Política Pública e Educação no Brasil}

O caso do Brasil se enquadra entre aqueles, tidos por Celso Furtado (1992) como países subdesenvolvidos, ocupando no mundo capitalista a posição de país periférico. Fato que, apesar das políticas recentes (Lula e Dilma), em alternativa às políticas neoliberais, não se opuseram ao sistema capitalista, nem às condições que caracterizavam à situação aludida por Furtado. Elevando, pois, a discussão ao nível internacional a análise reprodutivista, é possível perceber o Brasil, na condição de país dominado e submisso, formado para esse papel por instituições ditas "multilaterais", que funcionam como Aparelho Ideológico, não simplesmente de um Estado, mas de um sistema, que está além de qualquer fronteira - o modo de produção capitalista, este a serviço dos países ricos.

Certamente que as políticas de Estado voltadas para a educação se assemelham, uma vez que em países como o Brasil se reproduz a mesma lógica das relações sociais dos países ricos com as particularidades e especificidades de sua história e da constituição das classes e das relações aqui estabelecidas. No entanto, pela realidade da periferia do mundo capitalista na qual o Brasil se localiza, tais relações tomam dimensões mais drásticas. Além de se manterem capitalistas, apesar de serem governadas por exesquerdistas, estão a servir de referência às classes dominantes mundiais nestes momentos de crise do capitalismo de forma global. Se na periferia, os problemas sociais são mais notórios, dada a dimensão que assumem, e persistem com tais governos, por outro lado, estão a desenvolver políticas (policy e politics) que amenizam as contradições, cooptam atores e institucionalizam lutas e amenizam a fome e a miséria de milhões sem questionar a apropriação desigual da riqueza produzida, da transformação da natureza ou da apropriação dos territórios. Logo, os problemas sociais 


\section{Claudionor Ferreira Araújo / Carlos Roberto da Silva Machado}

gerados pelas relações desiguais, inerentes ao capitalismo e desses processos de apropriação desigual, ganham aqui maiores dimensões. Daí a intervenção estatal para preservar a classe dominante (mesmo que de forma contraditória e permeada de conflitos por parte ou setores destas classes dominantes) de quaisquer intempéries sociais que coloquem em risco o sistema e sua governabilidade como um todo.

As ações públicas são, assim, vistas por autores brasileiros, como Carlos R. Cury, para quem o Estado tem mesmo a obrigação da intervenção para alcançar essa reversão. Se se trata de

\footnotetext{
um serviço público, ainda que ofertado também pela iniciativa privada, por ser direito de todos e dever do Estado, é obrigação deste interferir no campo das desigualdades sociais e, com maior razão, no caso brasileiro, no terreno das hierarquias sociais, como fator de redução das primeiras e eliminação das segundas, sem o que o exercício da cidadania ficaria prejudicado a priori. (grifo do autor). (CURY, 2008, p. 302).
}

Segundo Cury, a educação teria um dever acima da instituição (iniciativa) que a oferece. E, quando pela iniciativa privada, em contradição a ela, por ser de sua natureza buscar a igualdade como pressuposto de sua função social. Mas, para isso, conforme Krawczyk: "o Estado devia cumprir também um papel central na pretendida igualdade dos sujeitos na escolarização pública que, entre outras coisas, significava a abolição das diferenças econômicas e culturais no espaço escolar" (KRAWCZYK, 2009 apud Dussel, 2000, p. 801).

Em termos da eficiência da educação como política pública, seja de Estado ou mesmo da iniciativa privada, sua avaliação depende daquilo que dela se espera como política social e daquilo que dela é pressuposto como uma ação dentro de um dado sistema. Se considerarmos que sua tarefa de promover igualdade numa dada sociedade, desenvolvida ou não, tem sido ineficaz, cabe inferir a que propósitos ela tem servido efetivamente.

Então, como vimos argumentando, numa sociedade de classes, como a brasileira, há que se reconhecer os conflitos que tais classes travam no seio do Estado, na luta pela implementação de políticas sociais, de uma parte, e na assimilação dessas demandas e sua conversão para o interesse do capital, de outra. Considerando a tendência defendida até aqui, cabe concluir que o esforço, dentro do modelo social capitalista, é vão. A política do Estado, diretamente advinda do interesse do capital, sempre será convertida em favor da proteção de tal interesse. 


\section{Claudionor Ferreira Araújo / Carlos Roberto da Silva Machado}

\section{Considerações finais}

Considerado o aspecto reprodutivo das ações do Estado, pelo qual todas as políticas, mesmo aquelas implementadas como "resposta" a um anseio popular, não é plausível admitir tais ações como conquistas ou "vitórias" sobre um inimigo, que mais que de pé, permanece soberano. O Estado burguês, nessa luta, não desempenha o papel de cenário, o campo onde são travadas as batalhas, mas constitui-se a principal arma da classe dominante, não só poderosa, mas também oculta, uma vez que não é entendida como tal, dado o seu caráter de "neutralidade" (PEREIRA, 2011). Ora, mesmo um campo de batalha só pode ser neutro quando não pertence a nenhuma das partes em conflito. E no caso do Estado, ora, ele é o Estado Capitalista, logo, pertence à classe dominante.

Como tal, o Estado faz refletir, inevitavelmente, em suas ações, as intenções da classe que impera sobre ele. É a lógica reprodutiva da estrutura e da superestrutura. As ações do Estado, em qualquer área, reproduzem as relações sociais. Dessa forma, no sistema de dominação capitalista, as políticas, mesmo as ditas "públicas", sempre refletirão os interesses privados dos detentores do capital. E quanto mais todos acreditarem que tais políticas sejam públicas, menos dificuldades essa classe dominante enfrentará para ver atendidas, por meio delas - logo, sem contestação -, as suas próprias demandas privadas.

$\mathrm{Na}$ área educacional, que está no nível da superestrutura, as políticas só se efetivam, de fato, na direção que o próprio Estado estiver caminhando. Caso contrário, não se efetivam. Gramsci (apud MANACORDA, 1990), por exemplo, quando elaborou a proposta da "Escola Unitária" supunha uma economia diferente da de mercado. Numa economia capitalista, tal proposta seria improvável.

O mesmo ocorre com a experiência de Paulo Freire (1989), cuja proposta metodológica pode aplicar-se efetivamente no contexto de um Estado recém emancipado, que tinha a emancipação política e econômica como mote para suas demais ações, inclusive educacionais. Tratava-se de educar os cidadãos a partir da nova realidade estrutural: a da liberdade e da transformação social.

Para as propostas de Gramsci e Freire, tem-se o seguinte esquema de reprodução: os conflitos permanecem na base (estes sempre permanentes, com maior ou menor intensidade); na estrutura, socialismo para aquele e emancipação político-

\begin{tabular}{|l|l|l|l|l|}
\hline Revista Dialectus & Ano 1 & n. 2 & Janeiro-Junho 2013 & p. 180-194 \\
\hline
\end{tabular}


econômica para este; e na superestrutura, a Escola Unitária e a educação emancipatória, respectivamente.

A educação, haja vista o seu papel central na reprodução das relações sociais numa sociedade de classes como a capitalista, não poderia promover o fim da desigualdade social. Seria ingenuidade esperar que qualquer política pública, especialmente a educação, seja eficiente na promoção da igualdade social, uma vez que a desigualdade e a exclusão são mesmo inerentes à democracia burguesa e ao modo de produção capitalista. Ora, isso está previsto desde Rousseau (1995) e Weber (1994). Embora a "igualdade" seja uma das premissas básicas do Estado "democrático", sua consecução não passa de uma falsa esperança, visto não representar mais que um mero discurso ideológico de uns poucos, os cidadãos de fato.

Nesses termos, qualquer cumprimento efetivo do seu papel social da educação, como de qualquer outra política, seria somente exequível noutro tipo de sociedade, regida por outro sistema de produção, servida por outro tipo de Estado, em que todos fossem mais que cidadãos de "direito".

\section{Referências Bibliográficas}

ALTHUSSER, Louis. Aparelhos ideológicos do Estado: nota sobre os aparelhos ideológicos de Estado (AIE). 2 ${ }^{\mathrm{a}}$. ed. Trad. W. J. Evangelista e M. L.Viveiros de Castro. Rio de Janeiro: Edições Graal, 1985.

\section{; BADIOU, Alain. Materialismo histórico e materialismo dialético. São}

Paulo: Global Editora, 1979.

ARAÚJO, Claudionor F. Conflitos ideológicos no texto da Lei 9.795/99: uma análise do discurso ideológico no texto da Lei de Educação Ambiental. / Dissertação (Mestrado em Educação - Políticas Públicas) - PPGED/ICED/UFPA, Belém, 2011.

BOURDIEU, P; PASSERON, J. C. A reprodução. Elementos para uma teoria do sistema de ensino. Rio de Janeiro: Francisco Alves, 1975.

.; WACQUANT, loïc. Una Invitación a La sociologia reflexiva. 2 ed.

Buenos Aires: Siglo XXI, 2008.

2010.

.;. Razões Práticas - sobre a teoria da ação. 10ª Ed. Campinas: Papyrus,

\begin{tabular}{|l|l|l|l|l|} 
Revista Dialectus & Ano 1 & n. 2 & Janeiro-Junho 2013 & p. 180-194 \\
\hline
\end{tabular}


Claudionor Ferreira Araújo / Carlos Roberto da Silva Machado

CARNOY, Martin. Educação, economia e Estado: base e superestrutura: relações e mediações. $4^{a}$. ed. Trad.: Dagmar Zibas. São Paulo: Autores Associados/Cortez, 1990. Coleção Polêmicas do Nosso Tempo. vol. 13.

CURY, Carlos Roberto Jamil. A educação básica como direito. Cadernos de Pesquisa, v. 38, n. 134, maio/ago. 2008.

FURTADO, Celso. Brasil, a construção interrompida. São Paulo: Paz e Terra, 1992.

HÖFLING, Eloísa de Mattos. Estado e políticas (públicas) sociais. Em: Cadernos Cedes, ano XXI, no 55, novembro/2001. Disponível em: http://www.ia.ufrrj.br/ppgea/ conteudo/conteudo-2008-1/HOFLING.pdf. Acesso em 20 Out 2009.

KRAWCZYK, Nora Rut. Políticas de regulação e mercantilização da educação: socialização para uma nova cidadania? Em: Educ. Soc., Campinas, vol. 26, n. 92, p. 799-819, Especial - Out. 2005). Disponível em: http://www.cedes.unicamp.br. Acesso em 20 Out 2009.

LEFEBVRE, Henri. Sociologia de Marx. Rio de Janeiro: FORENSEUNIVERSITÁRIA, 1966. 1976.

Hegel, Marx, Nietzsche, ou o reino das sombras. Lisboa: Editora Ulisseia.

MACHADO, Carlos RS. Contribuição acerca das políticas públicas da educação e o paradigma emergente. Revista ECCOS, SP, v.8, n.1, jun./jul. 2006. In. http://www.redalyc.com/src/inicio/ArtPdfRed.jsp?iCve=71580111] <Acesso 25.10.2012>

A Educação no extremo sul do Brasil: contribuições aos estudo e à pesquisa da (in) sustentabilidade da qualidade e da democracia nas políticas educacionais. Rio Grande: Editora da FURG, 2011.

; MARTINS, César (org.). Leituras do pensamento de Henri Lefebvre: aproximações e desafios. Rio Grande: Editora da FURG; 2011.

MANACORDA, M. A. História da educação: da Antiguidade aos nossos dias. São Paulo: Cortez; Autores Associados, 1990.

MARX, Karl. O Capital; crítica da economia política. 7ª ed. São Paulo: Difel S.A., 1982.

MÉSZÁROS, István. A educação para além do capital. São Paulo: Boitempo, 2005.

ORTIZ, Renato (org.). A sociologia de Pierre Bourdieu. São Paulo: Olho Dágua, 2003.

PEREIRA, Alexandre M. O programa de educação ambiental dos grandes empreendimentos (VALE S/A) na Amazônia e as implicações sócioambientais nas comunidades do entorno: o caso da Vila Bom Jesus no município de Canaã dos

\begin{tabular}{|l|l|l|l|l|} 
Revista Dialectus & Ano 1 & n. 2 & Janeiro-Junho 2013 & p. 180-194 \\
\hline
\end{tabular}


Claudionor Ferreira Araújo / Carlos Roberto da Silva Machado

Carajás / Dissertação (Mestrado em Gestão de Recursos Naturais e Desenvolvimento Local na Amazônia) - PPGEDAM/NUMA/UFPA, Belém, 2011.

RANCIÈRE, Jacques. A partilha do sensível: estética e política. Tradução: Mônica Costa Netto. São Paulo: EXO Experimental / Editora 34, 2005.

ROUSSEAU, Jean-Jacques. Do contrato social. Trad. Maria Constança Peres Pissara. Petrópolis:Vozes, 1995.

SANTOS, Reginaldo Souza et al. Compreendendo a natureza das políticas do estado capitalista, 2005.2 Disponível em: http://www.sep.org.br/artigo/_645_e6c1951b2527acfdcdaaa 7342b7456b2.pdf?PHPSESSID=93c69bf512f15aacfd4cac3a9c. Acesso em 20 Out 2009.

SAVIANI, Demerval. Pedagogia histórico-crítica: primeiras aproximações. $10^{\mathrm{a}}$. ed. São Paulo: Autores Associados: 2008. Coleção Educação Contemporânea.

SOREL, Georges. Reflexões sobre a violência. São Paulo: Martins Fontes, 1992.

TEIXEIRA, Elenaldo Celso. O Papel das Políticas Públicas no Desenvolvimento Local e na Transformação da Realidade. Disponível em: http://www.dhnet.org.br/dados/ cursos/aatr2/a_pdf/03_aatr_pp_papel.pdf. Acesso em 20 Out 2009.

WEBER, Max. A ética protestante e o espírito do capitalista. $8^{\text {a }}$ ed. São Paulo: Pioneira, 1994. 